\title{
Studi Meta-Analisis: Hubungan Antara Motivasi Kerja dengan Kinerja
}

\section{Meta-Analysis Study: A Correlation Between Work Motivation and Performance}

\author{
Rahmat Syaibani* \\ Program Studi Psikologi Islam, Sekolah Tinggi Agama Islam Aceh Tamiang, Indonesia \\ Disubmit: 23 April 2021; Diproses: 25 April 2021; Diaccept: 01 Agustus 2021; Dipublish: 02 Agustus 2021 \\ *Corresponding author: E-mail: rahmatsyaibani14@gmail.com
}

\begin{abstract}
Abstrak
Kinerja karyawan merupakan suatu bentuk hasil keseluruhan dari proses kerja selama periode tertentu pada sebuah perusahaan yang telah dilakukan oleh karyawan dalam menjalankan tugas dan tanggung jawabnya sebagai seorang karyawan. Telah banyak dilakukan penelitian tentang kinerja karyawan dan salah satunya adalah motivasi karyawan yang memiliki keterkaitan pada tinggi dan rendahnya kinerja seseorang karyawan. Pada penelitian ini dilakukan dengan menggunakan teknik studi meta-analisis dan bertujuan untuk meneliti hubungan antara motivasi kerja dan kinerja karyawan. Penelitian ini melakukan reviu yang melibatkan 7 studi jurnal yang berkaitan dengan motivasi kerja dan kinerja karyawan pada 10 tahun terakhir dan dengan jumlah responden sebanyak 446. Hasil dari penelitian studi meta-analisis ini menunjukkan korelasi yang small effect size sebesar $\mathrm{r}=0,46(95 \% \mathrm{CI}=0.235,0.635)$ confidance intervalnya akan ada heterogeneity $I^{2}=84.6 \%$ maka meta-analisis ini menggunakan random effect size. Dari hasil tersebut mengindikasikan bahwa motivasi kerja kurang berkorelasi dengan kinerja karyawan secara langsung dikarenakan memiliki small effect size . hal ini mengisyaratkan ada variabel-variabel lain yang memiliki nilai korelasi yang lebih besar dari pada motivasi kerja.
\end{abstract}

Kata Kunci: Kinerja Karyawan; Motivasi kerja; Meta-Analisis.

\begin{abstract}
A Employee performance is a form of the overall result of the work process during a certain period in a company that has been carried out by employees in carrying out their duties and responsibilities as an employee. There have been many researches on employee performance and one of them is employee motivation which is related to the high and low performance of an employee. This research was conducted using a meta-analysis study technique and aimed to examine the relationship between work motivation and employee performance. This study conducted a review involving 7 journal studies related to work motivation and employee performance in the last 10 years and with a total of 446 respondents. The results of this meta-analysis study showed a small effect size correlation of $r=0.46$ (95 \%CI=0.235,0.635) the confidence interval will have heterogeneity ${ }^{2}=84.6 \%$, so this meta-analysis uses a random effect size. These results indicate that work motivation is not directly correlated with employee performance because it has a small effect size. this implies that there are other variables that have a greater correlation value than work motivation.
\end{abstract}

Keywords: Employee Performance; Work motivation; Meta-Analysis.

DOI: https://doi.org/10.51849/j-p3k.v2i2.104

Rekomendasi mensitasi :

Syaibani, R. (2021), Studi Meta-Analisis: Hubungan Antara Motivasi Kerja dengan Kinerja. Jurnal Penelitian Pendidikan, Psikologi dan Kesehatan (J-P3K), 2 (2): 182187. 


\section{PENDAHULUAN}

Kinerja dari seorang karyawan merupakan salah satu faktor yang cukup penting dalam sebuah perusahaan, dikarenakan kinerja karyawan merupakan salah satu yang menentukan bergerak maju atau tidaknya sebuah perusahaan. Bila karyawan kinerjanay tidak maksimal ataupun optimal maka kemungkinan yang akan terjadi nantinya adalah merosotnya produktifitas ataupun perkembangan perusahaan, namun sebaliknya apabila karyawan memiliki kinerja yang maksimal dan optimal maka hal ini akan mempengaruhi produktifitas ataupun perkembangan dari sebuah perusahaan.

Apabila karyawan memiliki kinerja yang optimal dan maksimal maka perusahaan akan mengalami kenaikan pada produktifitas ataupun perkembangannya, perusahaan akan bergerak pada kemajuan, bukan kemerosotan. Kinerja merupakan suatu bentuk perilaku yang nyata dan ditampilkan setiap orang sebagai prestasi kerja yang dihasilkan oleh karyawan yang sesuai dengan perannya dalam perusahaan (Veithzal, 2004).

Turunnya produktifitas ataupun merosostnya perkembangan perusahaan serta tujuan perusahaan yang belum tercapai mendorong pihak pimpinan perusahaan untuk mencari solusi bagaimana mendorong dan mendapatkan nilai yang lebih untuk dapat memecahkan masalah, serta mendongkrak keberlangsungan perusahaan, antara lain yaitu penerapan program pengembangan sumber daya manusia (SDM) dengan cara meningkatkan motivasi kerja karyawan.

Dalam melakukan penerapan program tersebut maka pimpinan perusahaan harus menunjang program tersebut, agar perusahaan mendapatkan peningkatan produktifitas ataupun mendongkraknya perkembangan perusahaan dikarenakan naiknya motivasi kerja para karyawan. Dengan naik nya motivasi karyawan maka perusahaan akan mendapatkan nilai lebih dalam hal produktifitas perusahaan sehingga dapat mendongkrak perkembangan perusahaan ke-arah yang lebih maju.

Motivasi kerja merupakan dorongan atau semangat kerja yang berasal dari dalam diri maupun dari luar diri untuk melakukan suatu pekerjaan dengan maksimal agar mendapatkan hasil kinerja yang lebih optimal. Didalam penelitian yang dilakukan oleh Ricky dkk (2016) dikatakan bahwa ada 4 alasan utama yang menjadi motivasi seseorang untuk bekerja yaitu: gaji bulanan, karir, berkarya dan mencari pengalaman. Kinerja merupakan hasil keseluruhan dari proses kerja selama periode tertentu, berdasarkan hasil penelitian terdahulu baik atau tidaknya kinerja karyawan dipengaruhi oleh banyak faktor diantaranya motivasi (Prabasari \& Netra, 2013), tuntutan kerja (Bakker et al., 2004),

gaya

kepemimpinan (Robbins, 1998; Trianingsih, 2007), budaya organisasi (Asfar Halim, 2009; Prihayanto, 2012), stress kerja (Robbins, 2001; Yang, C. Y., \& Hung, C. H. 2012).

Begitu banyak faktor yang mempengaruhi kinerja karyawan kemudian pada penelitian ini menggunakan salah satu faktor saja yaitu: motivasi kerja. Berdasarkan penelitian penelitian yang telah dilakukan sebelumnya menunjukkan bahwa motivasi kerja dapat mempengaruhi tinggi rendahnya kinerja seseorang seperti pada penelitian yang dilakukan oleh Motulo dkk 
(2016) hasil penelitian menunjukkan bahwa ada hubungan yang positif dan nyata antara motivasi kerja dengan kinerja karyawan. Hal tersebut juga didukung oleh penelitian yang dilakukan oleh Jaya \& Ningsih (2018) bahwa menunjukkan terdapat hubungan yang nyata antara motivasi kerja dengan kinerja karyawan. Namun sebaliknya pada penelitian yang dilakukan oleh Salawangi dkk (2018) bahwa tidak terdapat hubungan yang signifikan antara motivasi kerja dengan kinerja karyawan.

Berdasarkan pemaparan diatas oleh peneliti didapatkan bahwa adanya perbedaan hasil dari penelitian sebelumnya baik korelasi yang positif ataupun tidak terdapat korelasi, yang signifikan ataupun tidak signifikan, peneliti bermaksud untuk melihat lebih mendalam dengan mengkaji hubungan motivasi kerja dengan kinerja karyawan dengan menggunakan pendekatan penelitian meta analisis

\section{METODE PENELITIAN}

Pada penelitian ini, peneliti melakukan penelusuran terhadap penelitian yang telah dilakukan sebelumnya yang berhubungan dengan hubungan antara motivasi kerja dengan kinerja karyawan dengan kata kunci; hubungan antara motivasi kerja dan kinerja karyawan. Pada penelitian ini data yang didapatkan diperoleh dari Google Scholar dan Researchgate.

Dari hasil penelusuran yang dilakukan oleh peneliti, peneliti menemukan 7 jurnal yang telah dipublikasi dengan berbahasa Indonesia yang berkaitan dengan hubungan antara motivasi kerja dengan kinerja karyawan, dan memuat adanya total responden $(\mathrm{N})$ serta adanya hasil dari korelasinya ( $r$ ). Metode yang digunakan pada penelitian ini adalah meta-analisis. Meta-Analisis merupakan penelitian yang menggunakan penelitian yang telah ada dan telah dgunakan oleh penelitian lalu dianalisis kembali secara sistematis dan kuantitatif untuk memperoleh sebuah hasil kesimpulan. Meta-Analisis menurut Card, 2012 (Utami \& Helmi, 2017) adalah suatu bentuk penelitian dari beberapa penelitian yang sudah dilakukan dan berfokus pada hasil yang telah ditemukan didalam penelitian-penelitian tersebut.

Pada penelitian ini peneliti menganalisis data dengan menggunakan website Meta-mar (free Online MetaAnalysis Service) dan menggunakan pedoman PRISMA (Preferred Reposrting Items for Systematic Review and Meta Analysis) Serta MARS (MetaAnalysis Reporting Standards). Kemudian kriteria dari jurnal yang akan digunakan pada penelitian ini yaitu jurnal dalam 10 tahun terakhir yang menggunakan metode kuantitatif korelasi. Berikut gambar 1 skema proses pencarian jurnal pada penelitian:

Proses awal screening dengan kata kunci motivasi kerja dan kinerja karyawan diperoleh 140 Jurnal

Dari penelusuran tersebut, lalu pencarian terkait dengan kata kunci hubungan atau korelasi diperoleh 18 jurnal

Menyeleksi kembali jurnal yang mencantumkan metode kuantitatif korelasi dan nilai korelasinya didapatkan 7 jurnal

Gambar 1. Foresplot-Fixed dan Random Effect Models 


\section{HASIL DAN PEMBAHASAN}

Dari hasil proses penelusuran yang dilakukan oleh peneliti maka diperoleh jurnal sebanyak 140 jurnal terkait motivasi kerja dan kinerja karyawan. Kemudian peneliti memfokuskan penelusurannya pada jurnal hubungan atau korelasi motivasi kerja dan kinerja karyawan sehingga diperoleh sebanyak 18 jurnal. Lalu peneliti pun menseleksi kembali hingga didapatkan 7 jurnal yang kemudian dipakai dalam penelitian.
Penelitian ini dilakukan dengan menggunakan 7 jurnal dengan jumlah responden sebanyak 446. Jurnal yang digunakan oleh peneliti diperoleh dari negara Indonesia saja, jumlah sampel bervariasi dari 30 hingga 158. Hasil penelusuran koefisien korelasi, jumlah sampel serta data jurnal yang sudah digunakan dapat dilihat pada tabel dibawah ini:

Tabel 1. Hasil Penelusuran Data Penelitian

\begin{tabular}{|c|c|c|c|}
\hline Peneliti dan Tahun & Judul Penelitian & Sample Size & Korelasi \\
\hline $\begin{array}{l}\text { Ricky Motulo, Billy Kountul, Don } \\
\text { R.G. Kabo, (2016) }\end{array}$ & $\begin{array}{l}\text { Hubungan Motivasi Kerja } \\
\text { dengan Kinerja Karyawan di } \\
\text { Hotel Gran Puri Manado }\end{array}$ & 158 & 0,485 \\
\hline Indra Jaya, Surya Ningsih, (2016) & $\begin{array}{l}\text { Hubungan Motivasi Kerja } \\
\text { dengan Kinerja Karyawan pada } \\
\text { Pt KAO Indonesia }\end{array}$ & 60 & 0,540 \\
\hline Cici Syafri Wenty (2015) & $\begin{array}{l}\text { Hubungan Motivasi } \quad \text { Kerja } \\
\text { dengan Kinerja Pegawai Dinas } \\
\text { Pendidikan Kabupaten Pesisir } \\
\text { Selatan }\end{array}$ & 56 & 0,254 \\
\hline $\begin{array}{l}\text { Glady Endayani Salawangi, Febi } \\
\text { K. Kolibu, Ribka Wowor (2018) }\end{array}$ & $\begin{array}{l}\text { Hubungan Motivasi Kerja } \\
\text { dengan Kinerja Perawat di } \\
\text { Instalasi Rawat Inap RSUD Liun } \\
\text { kendage Tahuna Kabupaten } \\
\text { Sangihe }\end{array}$ & 64 & 0,076 \\
\hline $\begin{array}{l}\text { Cesilia M. Karawanep, Adisti A. } \\
\text { Rumayar, Sulaemana Engkeng } \\
\text { (2021) }\end{array}$ & $\begin{array}{l}\text { Hubungan antara Motivasi Kerja } \\
\text { dengan Kinerja Pegawai Di } \\
\text { Puskesmas } \\
\text { Kabupaten Biak Provinsi Papua }\end{array}$ & 30 & 0,019 \\
\hline Yuliawati, Septi Widiyanti (2013) & $\begin{array}{l}\text { Hubungan Motivasi Kerja } \\
\text { dengan Kinerja Pegawai di } \\
\text { Program Studi Kebidanan Metro }\end{array}$ & 39 & 0,715 \\
\hline $\begin{array}{l}\text { Natasya D. Dungus, Nova } H . \\
\text { Kapantow, Frans J. O. Pelealu }\end{array}$ & $\begin{array}{l}\text { Hubungan Antara Motivasi } \\
\text { Kerja dengan Kinerja Pegawai } \\
\text { Puskesmas Ranotana Weru } \\
\text { Kecamatan Wanea Kota Manado }\end{array}$ & 39 & 0,796 \\
\hline
\end{tabular}


Pengujian data meta-analisis ini dilakukan dengan menggunakan website Meta-mar (Free Online Meta-Analysis Service) kemudian peneliti menginput judul penelitian jumlah subjek yang digunakan dan hasil dari korelasi dari tiap tiap penelitian.

Selanjutnya hasil outputnya memuat beberapa hal yaitu Inconsistency (I2), Hedges-olkin random atau fixed effects dan Foresplot. Untuk mengetahui bagian yang menunjukkan hasil besaran efek yakni dengan melihat hasil hedges-olkin random atau fixed effects.

Kemudian untuk menentukan antara random atau fixed dengan melihat berapa besar persentase inkonsistensi (I2). Apabila hasil inkonsistensi memiliki persentase kurang dari sama dengan 80\% maka fixed effects yang digunakan. Akan tetapi, apabila nilai persentasenya lebih dari 80\% maka random effects yang digunakan. Untuk korelasi meta-analisis perhitungannya apabila nilai effects size berada dibawah 0,1 dan berada sampai rentang 0,3 maka memiliki small effects size. Sementara apabila nilai effects size berada pada rentang 0,3 sampai 0,5 maka memiliki medium effects size. Kemudian jika nilai effects size lebih dari 0,5 maka memiliki large effects size.

Berdasarkan data diatas dari 7 jurnal yang telah di analisis dan telah dihitung maka studi korelasi pada penelitian ini menunjukkan bahwa terdapat hubungan negatif antara variabel motivasi kerja dengan kinerja karyawan. Hasil statistik menunjukkan inkonsistensi sebesar $84,6 \%$ $>80 \%$, maka random effects size dipilih. Lalu nilai random effects size yaitu sebesar $0,46(95 \% \mathrm{CI}=0.235,0.635)$ yang berarti terdapat small effects size antara motivasi kerja terhadap kinerja seseorang karyawan. Berikut merupakan tabel lampiran hasil dari meta-analisis dan hasil random effect models menggunakan website Meta-mar (Free Online MetaAnalysis Service).

Tabel 2. Hasil Fixed dan Random Effects Models

\begin{tabular}{l|l|l|l|l|l|l|l}
\hline & $\begin{array}{l}\text { Fish } \\
\text { er Z }\end{array}$ & r & SE & $\begin{array}{l}95 \% \\
\text { CI }\end{array}$ & $\begin{array}{l}\text { z } \\
\text { sor } \\
\text { e }\end{array}$ & $\begin{array}{l}\text { p } \\
\text { value }\end{array}$ & $\begin{array}{l}\text { Heterogen } \\
\text { eity }\end{array}$ \\
\hline $\begin{array}{l}\text { Fixed } \\
\text { Effect }\end{array}$ & 0.49 & 0.4 & $\begin{array}{l}0.04 \\
9\end{array}$ & $\begin{array}{l}{[0.37} \\
3,0.52 \\
4]\end{array}$ & $\begin{array}{l}10.0 \\
36\end{array}$ & 0.0 & $\begin{array}{l}\mathrm{I}^{2}=84.6 \% \\
\mathrm{Chi}^{2}=39.059, \\
\mathrm{df}=6\end{array}$ \\
\hline $\begin{array}{l}\text { Model } \\
\text { Rando }\end{array}$ & 0.49 & 0.4 & 0.13 & $\begin{array}{l}{[0.23} \\
5,0.63\end{array}$ & $\begin{array}{l}3.79 \\
6\end{array}$ & 0.0001 & $\begin{array}{l}\mathrm{I}^{2}=84.6 \%, \\
\mathrm{Tau}^{2}=0.098\end{array}$ \\
$\begin{array}{l}\text { Effect } \\
\text { Model }\end{array}$ & & 6 & & $5]$ & & & \\
\hline
\end{tabular}

Berdasarkan perhitungan uji statistika meta-analisis diatas antara motivasi kerja dan kinerja karyawan diperoleh hasil small effect size $(0,46)$ maka dapat diartikan motivasi kerja memberikan sedikit efek pada kinerja karyawan. Hasilnya yang kecil dan sedikitnya efek tersebut dapat disebabkan oleh faktor faktor lain yang mempunyai pengaruh dan efek yang lebih besar untuk mempengaruhi kinerja karyawan seperti: stress kerja, gaya kepemimpinan, budaya organisasi, bahkan tuntutan kerja.

$$
\text { Menurut Yang }
$$

mengungkapkan bahwa terdapat beberapa faktor yang dapat mempengaruhi kinerja karyawan salah satunya adalah stres kerja. Hal ini sejalan dengan penelitian yang dilakukan oleh Komarudin (2018) bahwa terdapat hubungan yang positif antara stres kerja dengan kinerja karyawan dengan nilai korelasi sebesar 0.601, sehingga dapat diartikan bahwa terdapat hubungan yang kuat antara stres kerja dengan kinerja karyawan.

Selain itu pada penelitian yang dilakukan oleh Agustina dkk (2019) juga menyatakan bahwa stres kerja mempunyai hubungan yang positif dengan kinerja karyawan di PT. Tunas Mobilindo Parama 
Jakarta Selatan dengan nilai korelasi sebesar 0.855 .

Kemudian pada penelitian yang dilakukan oleh Gultom (2014) menambahkan selain dari stress kerja ternyata ada faktor lain yang mempengaruhi kinerja karyawan yaitu budaya organisasi, dimana budaya organisasi memiliki hubungan yang positif dengan kinera karyawan pada perusahaan Gas Negara Tbk. Medan dengan nilai regresinya sebesar 0,348 .

Maka dengan demikian pada penelitian meta-analisis antara motivasi kerja dengan kinerja karyawan hanya memberikan efek yang kecil disebabkan oleh adanya faktor-faktor variabel yang lebih besar dalam memberikan pengaruh pada kinerja karyawan sendiri dari ada variabel motivasi kerja.

\section{SIMPULAN}

Kesimpulan pada penelitian ini menunjukkan bahwa motivasi kerja memiliki efek small to large effects dalam mempengaruhi kinerja karyawan. Dimana motivasi kerja memberikan efek yang kecil atau bisa disebut kurang signifikan terhadap kinerja karyawan, dikarenakan dipengaruhi oleh beberapa faktor lain yang mempengaruhi kinerja karyawan seperti: stres kerja, budaya organisasi, dan lainnya.

Saran untuk penelitian selanjutnya pada penelitian studi meta-analisis adalah penulis dapat mengkategorikan responden penelitian dikarenakan setiap responden memiliki dinamika motivasi kerja yang berbeda beda.

\section{DAFTAR PUSTAKA}

Agustina, T., Lestari, N., Yanti, R., \& Shella. (2019). Hubungan Stres Kerja terhadap Kinerja Karyawan pada PT Tunas
Mobilindo Parama Jakarta Selatan. Jurnal $B S I, 17(2)$.

Gultom, D. K. (2014). Pengaruh Budaya Organisasi Perusahaan dan Motivasi terhadap Kinerja Karyawan pada PT Perusahaan Gas Negara (Persero) Tbk. Medan. Jurnal Manajemen \& Bisnis, 14(02), 176-184.

Jaya, I., \& Ningsih, S. (2018). Hubungan Motivasi Kerja Dengan Kinerja Karyawan Pada Pt Kao Indonesia. JIMFE (Jurnal Ilmiah Manajemen Fakultas Ekonomi), 2(1), 20-29. https://doi.org/10.34203/jimfe.v2i1.72 8

Komarudin. (2018). Hubungan Stress kerja Dengan Kinerja Pegawai pada Pt Herona Express Kantor Pusat Pamulang. Jurnal Kreatif, 6(2), 53-65.

Motulo, R., Kountul, B., \& Kabo, D. R. G. (2016). Hubungan Motivasi Kerja dengan Kinerja Karyawan di Hotel Gran Puri Manado. 3(2), 23-28.

Salawangi, G. E., Kolibu, F. K., \& Wowor, R. (2018). Jurnal KESMAS, Vol. 7 No. 5, Hubungan Motivasi Kerja dengan Kinerja Perawat di Instalaasi Rawat Inap RSUD Liun Kendage Tahuna Kabupaten Sangihe. Kesmas, 7(5).

Veithzal, R. (2004). Manajemen Sumber Daya Manusia Untuk Perusahaan. Dari Teori Ke Praktik. PT. Raja Grafindo Persada.

Yang, C., \& Hung, C. H. (2012). Effect of Recreational Involvement on Stress Relief and Job Performance in Restaurant Workers: The Moderating Role of Psychological Contract. Pakistan Journal of Statistic., 28(5), 525-535. 